\title{
The Perception and Attitudes Towards City Garbage Management: A First Analysis
}

Francesco Ceresia

Assistant Professor, Department of Political Science and International Integration, University of Palermo

Rosa Marìa Molina Moreno

Psychologist, Department of Health Psychology, University Miguel Hernández of Elche

Ángel Solanes Puchol

Professor, Department of Health Psychology, University Miguel Hernández of Elche

\begin{abstract}
The main aim of this paper is to to explore the perception and attitude of people toward an important issue like the City Garbage Management. A new Survey Questionnaire to measure the perception and attitudes towards city garbage management has been developed by the Authors, in order to realize a very first analysis of compatibility of the Comprehensive Action Determination Model - CADM (Klöckner, 2013) with City Garbage Management issues. To test the application of the CADM model to City Garbage Management, a simple linear regression was calculated to predict the dependent variables based on predictor variables according the CADM model. The linear regression analysis shows a first confirmation of the CADM model applied to the perception and attitudes towards city garbage management.
\end{abstract}

Keywords: environmental psychology; Regression analysis; city garbage management; attitude

\section{Introduction}

People exercise influence on the environment and - at the same time - this same environment influences people who are interacting with it. As Gifford (2012) states: "Environmental psychology is the study of transactions between individuals and their built and natural settings".

Today people have to facet with several environmental problems and, usually, they don't act in a correct way to prevent environmental risks for the following reasons: low attitude and preparation to prevent the risks, the hasty and sometimes inappropriate responses to mitigate the risks and a misperception of them. National and international efforts are needed to counteract the big number of global environmental challenges that we must face (Klöckner, 2013).

The environmental psychology is a research field focused on the understanding of the keys and processes which are carrying these environmental challenges, to prevent them and minimize their negative responses (Hertwich, 2005). As important factors to get this mission we found the technologic development, the national and international policies and the individual behavior, especially the household behavior highlighted by Hertwich (2005). Dietz, Gardner, Gilligan \& Stern (2009) underlined several aspects that can reduce the negative impact of the human behaviors on the environment.

Around the environmental psychology there are several theoretical frameworks, due to the number of factors influencing the interaction people-environment (Gifford, 2012; Newell, McDonald, Brewer \& Hayes, 2014).

\section{The theoretical backgroung}

Lots of psychological theories have tried to shed light on the interaction between people and environment, but is it difficult to find a exhaustive model that explains and represents the overall human behavior in connection with the environment, due to the already named complexity and variety of behaviors and the amount of factors that influence them (Dubois \& Dubois, 2012; Uzzell \& Räthzel, 2009). 
An interesting attempt to provide such a general model is the Comprehensive Action Determination Model (CADM) (Klöckner, 2013; Klöckner \& Blöbaum, 2010).

CADM model is consistent with the theory of Planned Behavior (TPB) of Ajzen (1991), a general model of deliberate behavior; the Norm Activation Model (NAM) of Schwartz (1977), that focuses on the personal norms as determinants of human behaviors; the Value Belief Norm Theory as adapted by Stern (2000), that explore the relation between general values, environmental beliefs and human behaviors; the Ipsative Theory of Behavior of Tanner (1999), that considers the situational characteristics, both objective and subjective, as behavior's predictors.

The most important assumption of CADM model is the three sources of direct influence on the individual behavior: intentional, situational and habitual. In addition, we find the normative processes that influence of indirect form. These four processes interact of complex form and cannot be considered of independent form (Klöckner and Blöbaum, 2010). Unlike the previous models, the influence of the personal and social norms takes form of normative processes together with the awareness of need and the awareness of consequences (fig 1. ). These processes are able to generate intentions and habits (Klöckner \& Blöbaum, 2010).

Figure 1. The Comprehensive Action Determination Model (CADM) by Klöckner \& Blöbaum (2010).

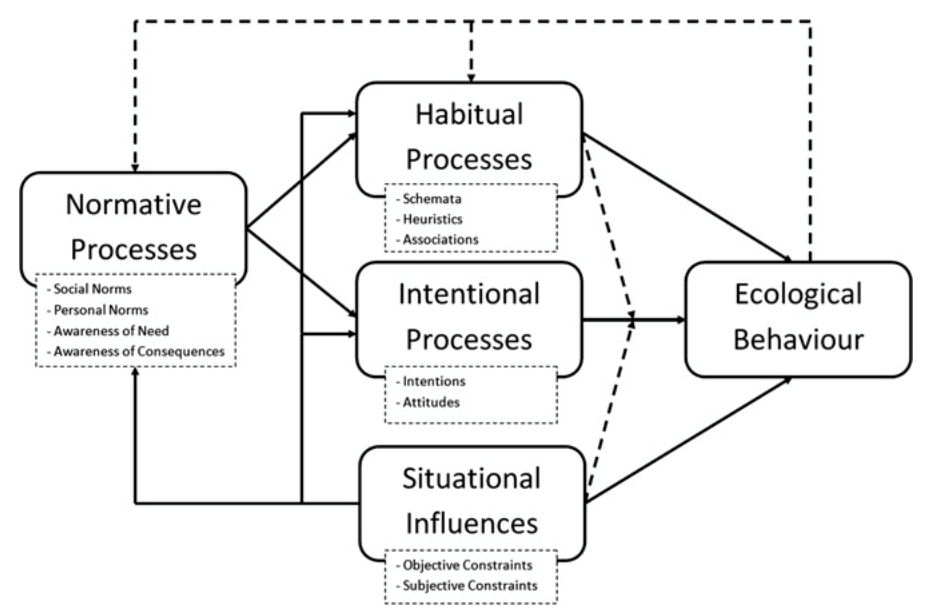

The model was used by Klöckner (2010) to predict the behavior of travel model choice, conduct considered important for the impact that it exercises on the environment and the results obtained were significant demonstrating a good adjustment between the model and the empirical data.

But in spite of the goods empirical results, this model showed several limitations. First, the limitations of the situation, because it only considers the car access, leaving of side other possible situation influences. Secondly, the limitation of the used population since one gave a strong process of self-selection, since those who took part in the study were the persons who had more interest in the topic (Klöckner and Blöbaum, 2010).

Klöckner (2013) developed a new general model introducing some changes. The intention of this new adjustment is that the new model could be applied to a wide range of environmental situations and behaviors.

Figure 2. The Comprehensive Action Determination Model (CADM) by Klöckner (2013) shows the results of the metaanalytical structural equation modelling based on the pooled correlation matrix. 


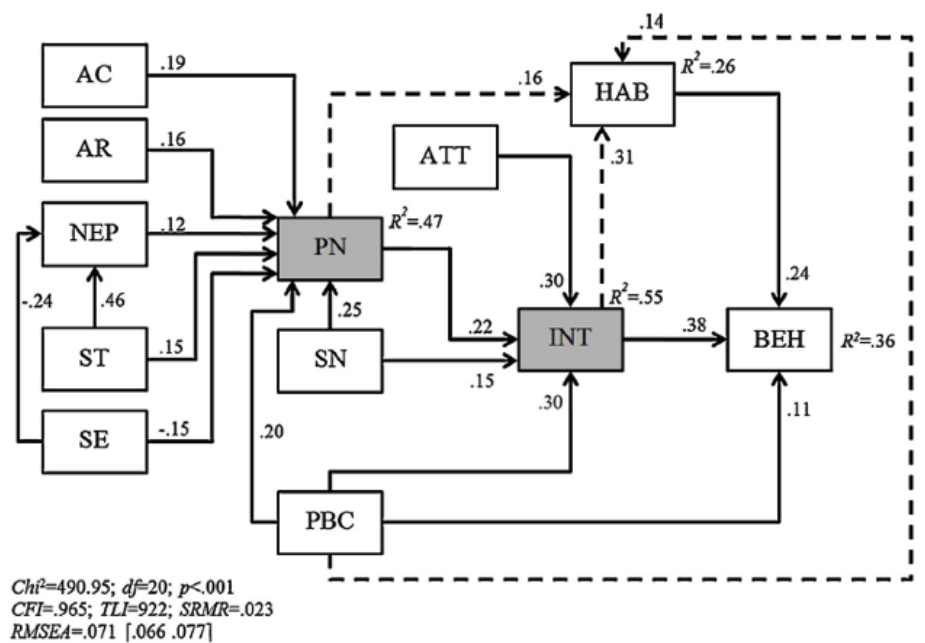

Notes. AC, awareness of consequences; AR, ascription of responsibility; ATT, attitudes; $B E H$, behavior; HAB, habit; INT, intention; NEP, new environmental paradigm; PBC, perceived behavioral control; PN, personal norm; SN, social norm; ST, self-transcendence values; SE, self-enhancement values.

Klöckner (2013) includes in this adjustment three new variables that activates the Personal Norms: the New Environmental Paradigm (NEP) and the Self-transcendence and Self-enhancement values, that at the same time influences in the ecological worldview (NEP), the first one in a positive way and the second one in a negative way. More in details, the selftranscendence value will increase the altruist behaviors, while the self-enhancement value will decrease it, and it will be more selfish. He also adds the Attitudes like a predictor that influences the intentions and the influence of the Habits on these Intentions.

The main aim of this paper is to to explore the perception and attitude of people toward an important issue like the City Garbage Management. A new Survey Questionnaire to measure the perception and attitudes towards city garbage management has been developed by the Authors, in order to realize a very first analysis of compatibility of the Comprehensive Action Determination Model (Klöckner, 2013) with City Garbage Management issues.

In fact, as underlined by Larose \& Pontonthe (2000), the problem of the increasing quantity of domestic garbage dumped in the environment, as a principal source of pollution, is assuming a growing importance in the scientific literature. The lack of an effective domestic garbage collection and management system in some European cities put in great evidence the negative impact of such human behavior on environment (Kortland, 1997).

\section{Materials and Methods}

\section{1 Participants}

This first study is based on the analysis of the perception and attitude of a high school group of students towards environmental issues, who are participating in an awareness campaign on the environment and ecological behavior organized by a management waste Company in an Italian Municipality. The questionnaire was then administered to 45 secondary school students aged between 15 and 17 years.

\section{2 Procedure}

To test the application of the CADM model to City Garbage Management, due the low number of subjects involved in the research, a simple linear regression was calculated to predict the dependent variables based on predictor variables according the CADM model (Klöckner, 2013).

\section{3 Measures}


To test the robustness of the CADM model if applied to City Garbage Management, a Survey Questionnaire to Measure the Perception and Attitudes towards City Garbage Management has been developed by the Authors. It consists in 40 items measured on a likert scale ranging from 1 to $5(1=$ strongly disagree, $5=$ strongly agree) that includes all the 12 CADM's factors (Klöckner, 2013). The content of the items have been adapted to the topic of our current study. More in details, the items of the questionnaire explore the three main city garbage topics as describing the relationship between people and their local environment: recycle and reuse, garbage on the street and the overfilling of landfills.

The following are the 12 factors of the proposed Survey Questionnaire to Measure the Perception and Attitudes towards City Garbage Management:

F1: Awareness of Consequences $(A C)$ refers to the perception of a causal relation between the own behaviors and its consequences with the environment. The factor is made up of 3 items. An example is the item: "If I recycle all my refusals I improve the quality of life of the future generations".

F2: Personal Norms $(P N)$ is about the feelings of moral obligation that directs the conduct to an ecologically positive behavior. The factor is made up of 3 items. An example of these items is: "For my values, I feel in duty to recycle all the refusals that I produced".

F3: Intention (INT) we define like the will to do an effort to demonstrate a certain behavior like recycle. The factor is made up of 2 items. An example of these items is: "I'm immediately strongly determined to recycle".

F4: Perceived Behavioral Control (PCB) consists on the degree in which persons we perceive that we have control at the moment of realizing certain environmental behaviors, like recycle or not throw garbage on the street. The factor is made up of 3 items. An example of these items is: "The circumstances make me very difficult to recycle".

F5: Habits (HAB) consist in the descriptions about the habitual behaviors related to two different areas of environmental behavior, the recycling and the fact of throwing garbage on the street. The factor is made up of 6 items. An example of these items is: "Recycling is something that I automatically do without almost thinking it".

F6: Behavior (BEH) is the conduct or conducts that are realized in response to a set of internal and external factors. The factor is made up of 3 items. An example of these items is: "In the last week, how many times have you happened to throw refusals on the street?".

F7: Ascription of Responsibility (AR) we can described like an acceptance of a consequences with environment has the own actions. The factor is made up of 3 items. An example of these items is: "To protect the environment is my personal responsibility".

F8: New Environmental Paradigm (NEP) consists in the people ecological worldview about topics like the overfilled of landfills, the steady increase of the residues, the limits of the natural resources and the environmental protection in itself. The factor is made up of 6 items. An example of these items is: "We cannot keep on throwing the refusals in the landfills".

F9: Self-Transcendence Value (ST) consists on the altruist or ecologic values, which mean accept the others like equals and there are orientated to the common good and to be care about the nature. The factor is made up of 3 items. An example of these items is: "Recycling improves the quality of the life and the comfort of the people that surround us".

F10: Self-Enhancement Value (SE), opposite the previous factor, consists in selfish values that are focusing on the own benefit over of the others. The factor is made up of 3 items. An example of these items is: "Recycling serves only to the fittings of harvest owners that get rich".

F11: Social Norms (SN) consists on the belief of the expectations that others have about how they expect us to behave in a respectfully way to environmental issues. The factor is made up of 3 factors. An example of these items is: "The people who I'm tied up expect that I don't throw the refusals on the street".

F12: Attitudes (ATT) consists on the sum of beliefs that the persons possess towards recycling, throwing garbage in the street, the overfilled of the landfills and the environmental care in general. The factor is made up of 2 items. An example of these items is: "Recycling is something very positive for everybody".

\section{Results}


The first result refers to the descriptive statistics for the 40 items of the survey questionnaire (tab 1).

We decided to delete the item 27 since all subjects have answered assigning always value 1 . This happens because item 27 refers to a specific garbage management behavior that is unusual for teenagers (Item 27: In the last month, noticing piles of rubbish or bulky waste abandoned on the street, did you reported the fact to those involved in the collection of such waste?).

Table 1. Descriptive statistics of the survey questionnaire items.

\begin{tabular}{lllll} 
Variable & Min & Max & Mean & SD \\
\hline V01 & 2 & 5 & 4,38 &, 747 \\
V02 & 2 & 5 & 4,47 &, 661 \\
V03 & 3 & 5 & 4,62 &, 535 \\
V04 & 1 & 5 & 3,33 & 1,187 \\
V05 & 1 & 5 & 4,51 &, 787 \\
V06 & 1 & 5 & 3,40 & 1,136 \\
V07 & 1 & 5 & 4,11 &, 935 \\
V08 & 2 & 5 & 3,80 &, 869 \\
V09 & 1 & 5 & 3,40 & 1,176 \\
V10 & 1 & 5 & 3,80 & 1,014 \\
V11 & 1 & 5 & 3,13 & 1,179 \\
V12 & 1 & 5 & 4,16 & 1,065 \\
V13 & 1 & 5 & 1,93 &, 915 \\
V14 & 1 & 5 & 4,07 &, 915 \\
V15 & 1 & 3 & 1,67 &, 739 \\
V16 & 2 & 5 & 4,53 &, 661 \\
V17 & 1 & 5 & 4,18 &, 984 \\
V18 & 1 & 5 & 4,53 &, 842 \\
V19 & 1 & 5 & 2,91 & 1,104 \\
V20 & 1 & 5 & 4,16 & 1,086 \\
\hline
\end{tabular}

\begin{tabular}{lllll} 
Variable & Min & Max & Mean & SD \\
\hline V21 & 1 & 5 & 3,69 & 1,104 \\
V22 & 1 & 5 & 4,38 & 1,029 \\
V23 & 1 & 5 & 3,04 & 1,445 \\
V24 & 1 & 5 & 3,60 & 1,053 \\
V25 & 1 & 5 & 2,87 & 1,290 \\
V26 & 1 & 5 & 4,16 & 1,021 \\
V27 & 1 & 1 & 1,00 & 0,000 \\
V28 & 2 & 5 & 4,47 &, 869 \\
V29 & 1 & 5 & 4,22 & 1,020 \\
V30 & 1 & 5 & 3,93 &, 986 \\
V31 & 1 & 5 & 4,07 & 1,009 \\
V32 & 1 & 5 & 3,11 & 1,369 \\
V33 & 2 & 5 & 4,31 &, 793 \\
V34 & 1 & 5 & 3,29 & 1,058 \\
V35 & 1 & 5 & 3,56 & 1,139 \\
V36 & 1 & 5 & 2,98 & 1,055 \\
V37 & 1 & 5 & 4,24 &, 830 \\
V38 & 1 & 4 & 2,07 &, 889 \\
V39 & 1 & 5 & 3,71 & 1,199 \\
V40 & 3 & 5 & 4,56 &, 586 \\
\hline
\end{tabular}

The following are the results of the simple linear regression to predict the dependent variables based on predictor variables according the CADM model (Klöckner, 2013). All the relationships between independent and dependent variables as depicted in the CADM model (Klöckner, 2013) have been statistically verified.

Causal Relationship \# 1: AC PN ----->

A significant regression equation was found $(F(1,43)=7,528, p<$. 009) with a $R 2$ of. 386. Participants' predicted Awareness of Consequences (AC) is equal to $8,101+0,357$ of Personal Norms (PN) value.

Causal Relationship \# 2: AR PN ------>

A significant regression equation was found $(F(1,43)=27,050, p<.000)$ with a $R 2$ of. 621. Participants' predicted Ascription of Responsibility (AR) is equal to 7, $802+0,439$ of Personal Norms (PN) value.

Causal Relationship \# 3: NEP PN ----->

A significant regression equation was found $(F(1,43)=9,111, p<$. 004) with a R2 of. 418. Participants' predicted New Environmental Paradigm (NEP) is equal to $6,785+0,256$ of Personal Norms (PN) value.

Causal Relationship \# 4: ST PN ------>

A significant regression equation was found $(F(1,43)=16,158, p<.000)$ with a R2 of. 523. Participants' predicted New Self-Transcendence Value (ST) is equal to 7, $283+0,430$ of Personal Norms (PN) value.

Causal Relationship \# 5: SE PN ----->>

A significant regression equation was found $(F(1,43)=17,311, p<.000)$ with a $R 2$ of. 536. Participants' predicted New Self-Enhancement Value (SE) is equal to 15, $869-0,542$ of Personal Norms (PN) value.

Causal Relationship \# 6: ST NEP -----> 
A significant regression equation was found $(F(1,43)=14,653, p<.000)$ with a $R 2$ of. 504. Participants' predicted New

Self-Transcendence Value (ST) is equal to $14,812+0,677$ of New Environmental Paradigm (NEP) value.

Causal Relationship \# 7: SE NEP ----.->

A significant regression equation was found $(F(1,43)=6,693, p<$. 013) with a R2 of. 367. Participants' predicted New

Self-Enhancement Value (SE) is equal to 26, $948-0,606$ of New Environmental Paradigm (NEP) value.

Causal Relationship \# 8: SN PN ----->

A significant regression equation was found $(F(1,43)=10,677, p<.002)$ with a $R 2$ of. 446. Participants' predicted Social Norms (SN) is equal to $9,304+0,311$ of Personal Norms (PN) value.

Causal Relationship \# 9: PBC PN ------>

A significant regression equation was found $(F(1,43)=11,700, p<$. 001) with a $R 2$ of. 462. Participants' predicted

Perceived Behavioral Control (PCB) is equal to $9,891+0,312$ of Personal Norms (PN) value.

Causal Relationship \# 10: PN INT ------>

A significant regression equation was found $(F(1,43)=38,442, p<.000)$ with a $R 2$ of. 687. Participants' predicted Personal Norms (PN) is equal to $-2,048+0,768$ of Intention (INT) value.

Causal Relationship \# 11: PN HAB ----->

A significant regression equation was found $(F(1,43)=24,910, p<.000)$ with a $R 2$ of. 606. Participants' predicted Personal Norms (PN) is equal to $5,217+1,374$ of Habits (HAB) value.

Causal Relationship \# 12: SN INT ------>

A significant regression equation was found $(F(1,43)=33,793, p<.000)$ with a $R 2$ of. 663. Participants' predicted Social Norms (PN) is equal to 1, $968+0,518$ of Intention (INT) value.

Causal Relationship \# 13: PBC INT ----->

A significant regression equation was found $(F(1,43)=21,250, p<.000)$ with a $R 2$ of. 575 . Participants' predicted Perceived Behavioral Control (PCB) is equal to $3,735+0,433$ of of Intention (INT) value.

Causal Relationship \# 14: PBC BEH ----->

A significant regression equation was found $(F(1,43)=17,062, p<.000)$ with a $R 2$ of. 533. Participants' predicted Perceived Behavioral Control (PCB) is equal to $3,916+0,352$ of of Behavior (BEH) value.

Causal Relationship \# 15: PBC HAB ----->

A significant regression equation was found $(F(1,43)=26,542, p<.000)$ with a $R 2$ of. 618 . Participants' predicted Perceived Behavioral Control (PCB) is equal to $13,985+0,944$ of of Habits (HAB) value.

Causal Relationship \# 16: ATT INT ----->

A significant regression equation was found $(F(1,43)=78,256, p<.000)$ with a $R 2$ of. 803. Participants' predicted Attitudes (ATT) is equal to $0,250+0,985$ of of Intention (INT) value.

Causal Relationship \# 17: INT BEH ----->

A significant regression equation was found $(F(1,43)=9,662, p<.000)$ with a $R 2$ of. 428. Participants' predicted Intention (INT) is equal to $4,280+0,375$ of of Behavior (BEH) value.

Causal Relationship \# 18: INT HAB ----->>

A significant regression equation was found $(F(1,43)=30,804, p<.000)$ with a $R 2$ of. 646 . Participants' predicted Intention (INT) is equal to $12,600+1,311$ of of Habits (HAB) value.

Causal Relationship \# 19: HAB BEH ----->

A significant regression equation was found $(F(1,43)=61,449, p<.000)$ with a R2 of. 767. Participants' predicted Habits $(\mathrm{HAB})$ is equal to $-0,352+0,331$ of of Behavior $(\mathrm{BEH})$ value 


\section{Discussion}

Basing on the analysis of the results, we can underline the role of all the 12 factors proposed by Klöckner (2013), used with regard to measuring the behaviors in that we were interested and we can affirm that the sample proves is showing his concern as the ecological topics about which were asked and also, they show worry about the importance of taking care of the environment.

The regression analysis shows a confirmation of the CADM model applied to the perception and attitudes towards city garbage management.

As already underlined, the main limitation of this research is the low number of subjects involved.

Further research have to deeply verify the perception and the attitude of people toward an ecologically important topic like is the management of the urban residues, more concretely on garbage recycling, not throwing garbage on the street and the management of the overfilled landfills issue.

\section{References}

[1] Ajzen, I. (1991). The theory of planned behavior. Organizational Behavior and Human Decision Processes, 50(2), 179-211. doi: 10. 1016/0749-5978(91)90020-T

[2] Dietz, T., Gardner, G. T., Gilligan, J., Stern, P. C., \& Vandenbergh, M. P. (2009). Household actions can provide a behavioral wedge to rapidly reduce U. S. carbon emissions. Proceedings of the National Academy of Sciences of the United States of America, 106, 18452-18456.

[3] Dubois, C. L., \& Dubois, D. A. (2012). Expanding the Vision of Industrial-Organizational Psychology Contributions to Environmental Sustainability. Industrial and Organizational Psychology, 5(4), 480-483.

[4] Gifford, R. (2012) Environmental Psychology. In V. S. Ramachandran (Ed. ) Encyclopedia of human behavior (2nd ed. ), pp. 54-60. San Diego: Academic Press.

[5] Hertwich, E. G. (2005). Life cycle approaches to sustainable consumption: a critical review. Environmental Science and Technology 39, 4673-4684.

[6] Kortland, J. (1997). Garbage: dumping, burning and reusing/recycling: students' perception of the waste issue. International Journal of Science Education, 19(1), 65-77.

[7] Klockner, C. A. (2013). A comprehensive model of the psychology of environmental behaviour - A metaanalysis. Global Environmental Change 23, 1028-1038.

[8] Klockner, C. A., \& Blöbaum, A. (2010). A comprehensive action determination model: Toward a broader understanding of ecological behavior using the example of travel model choice. Journal of Environmental Psychology, 30, 574-586.

[9] Larose, F., \& Ponton, M. (2000). Locus of control and perceptions of environmental risk factor: Inhabitants of slums facing domestic garbage. Swiss Journal of Psychology, 59(3), 137.

[10] Newell, B. R., McDonald, R. I., Brewer, M., \& Hayes, B. K. (2014). The psychology of environmental decisions. Annual Review of Environment and Resources, 39, 443-467.

[11] Schwartz, S. H. (1977). Normative influences on altruism. In L. Berkowitz (Ed. ). Advances in experimental social psychology (Vol. 10, pp. 221-279). New York: Academic Press

[12] Stern, P. C. (2000). Toward a coherent theory of environmentally significant behavior. Journal of Social Issues, 56(3), 407-424.

[13] Tanner, C. (1999). Constraints on environmental behaviour. Journal of Environmental Psychology, 19(2), 145157. doi:10. 1006/jevp. 1999. 0121

[14] Uzzell, D., \& Räthzel, N. (2009). Transforming environmental psychology. Journal of Environmental Psychology, 29(3), 340-350. 